\title{
Enhancement of Mononuclear Procoagulant Activity by Platelet 12-Hydroxyeicosatetraenoic Acid
}

Roberto Lorenzet, Julian Niemetz, Aaron J. Marcus, and M. Johan Broekman

Departments of Medicine, Divisions of Hematology-Oncology, Veterans Administration Medical Centers, Bronx, New York 10468 and New York, New York 10010; Mount Sinai Medical School, New York 10029; and Cornell University Medical College, New York 10021

\begin{abstract}
Platelets induce generation of procoagulant tissue factor activity (TFa) by mononuclear leukocytes, and also enhance the TFa induced by endotoxin. Our present investigation demonstrated that arachidonic acid, which by itself had no effect on mononuclear TFa, greatly enhanced platelet-induced TFa. The effect was concentration dependent for both platelets and arachidonate (1-20 $\mu \mathrm{M}$ ); other fatty acids tested were inactive. The enhancing effect of arachidonate was more pronounced if platelets were exposed to aspirin, suggesting lipoxygenase product involvement. Production of 12-hydroxyeicosatetraenoic acid (12-HETE) was demonstrated biochemically in aspirin-treated platelet/arachidonate/mononuclear cell preparations that generated high levels of TFa. The enhancing role of 12-HETE was verified as follows. Addition of platelet-derived or synthetic 12-HETE amplified endotoxin-induced TFa more than threefold: Other lipoxygenase products were inactive. Enhancement of mononuclear cell TFa by 12-HETE represents a newly described biological function for this eicosanoid in cell-cell interactions between platelets and mononuclear cells.
\end{abstract}

\section{Introduction}

Upon stimulation with endotoxin, leukocytes develop a powerful procoagulant activity; detectable in vivo and in vitro. In humans, this procoagulant activity is most often of the tissue factor type (TFa). ${ }^{1}$ In addition, after infusion of endotoxin-stimulated leukocytes (possessing TFa) into rabbits, a defibrination syndrome, accompanied by thrombi in multiple organ systems, occurs (1, 2). The clinical importance of TFa in endotoxemia has recently been further underscored by the striking positive correlation be-

Portions of this work were presented at the Annual Meeting of the American Federation for Clinical Research, Washington, DC, May, 1984, and have been published in abstract form (1984. Clin. Res. 32:498A).

Dr. Lorenzet is on a leave of absence from the Mario Negri Institute in Milan, Italy. Dr. Broekman is an Established Investigator of the American Heart Association. Address correspondence to Dr. Niemetz, Veterans Administration Medical Center, 130 Kingsbridge Rd., Bronx, NY 10468. 1986.

Received for publication 23 October 1985 and in revised form 7 March

1. Abbreviations used in this paper: 5,12-diHETE, 5,12-dihydroxyeicosatetraenoic acid; 5-HETE, 5-hydroxyeicosatetraenoic acid; 12-HETE, 12-hydroxyeicosatetraenoic acid; $\mathrm{LTB}_{4}$, leukotriene $\mathrm{B}_{4} ; \mathrm{LTC}_{4}$, leukotriene $\mathrm{C}_{4} ; \mathrm{LTD}_{4}$, leukotriene $\mathrm{D}_{4} ; \mathrm{TFa}$, tissue factor activity; TLC, thinlayer chromatography.

The Journal of Clinical Investigation, Inc.

Volume 78, August 1986, 418-423 tween elevated leukocyte procoagulant activity and mortality, reported in patients with meningococcemia (3).

Several other biological substances have been shown to induce leukocyte TFa. These include the hydrolytic fragment of the fifth component of complement (4), phytohemagglutinins $(5)$, certain plasma lipoproteins $(6,7)$, antigen-antibody interactions (8), and malignant cells (9).

The effector leukocyte in this system is the macrophage (10)monocyte $(5-7,11)$. $T$ lymphocytes have been proposed as modulators of TFa, since they can enhance the effect of certain stimuli (5). Some investigators have suggested that the requirement for T lymphocytes in the induction of TFa is absolute (12).

The platelet is another blood component known to be involved in the induction-modulation of TFa (13-15). The platelet contribution is complex and can be summarized as follows: $(a)$ platelets and platelet membranes enhance endotoxin-induced $\mathrm{TFa},(b)$ platelets alone induce TFa, and $(c)$ platelet cytosol stimulates development of a procoagulant activity that is not TFa (15). The present study was undertaken after preliminary experiments indicated that platelet eicosanoid metabolism may contribute to the development of leukocyte TFa. Our results indicate that 12-hydroxyeicosatetraenoic acid (12-HETE), a metabolic product of the platelet lipoxygenase pathway, enhances the effect of endotoxin on leukocyte TFa. This platelet-leukocyte interaction was not elicited when other lipoxygenase products were tested. Thus, the present work describes a novel functional parameter for 12-HETE.

\section{Methods}

Blood was obtained from healthy volunteers and anticoagulated with 0.1 vol $4 \%$ trisodium citrate-dihydrate. Citratre phosphate dextrose adenine 1 whole blood, or leukocyte concentrates were also used (New York Blood Center, New York, NY). For leukocyte separations, whole blood was centrifuged at $280 \mathrm{~g}$ for $15 \mathrm{~min}$ at $4^{\circ} \mathrm{C}$ and the platelet-rich plasma removed. The sedimented cells were diluted to initial volume with citrate-saline-albumin ( 1 vol $4 \%$ citrate, 5 vol $0.15 \mathrm{M} \mathrm{NaCl}, 1 \%$ human albumin). After centrifugation as above, the platelet-rich supernate was removed. The sedimented cells were again diluted with citrate-salinealbumin to twice the original volume and layered onto Ficoll-Hypaque (16) (Pharmacia Fine Chemicals, Piscataway, NJ) and centrifuged at 400 $g$ for $40 \mathrm{~min}$ at $12^{\circ} \mathrm{C}$. The resulting mononuclear cells, which still contained platelets, were subsequently washed by resuspension in citratesaline-albumin, sedimented at $300 \mathrm{~g}$ for $10 \mathrm{~min}$, and the supernatant decanted. This step was performed three to six times, depending upon the degree of platelet contamination. In some experiments, when greater platelet paucity was deemed desirable, dextran sedimentation of whole blood (16) followed by three washes in citrate-saline-albumin preceded the Ficoll-Hypaque step, which in turn was followed by 3 more washes.

When leukocyte concentrates were used, cells were diluted fourfold in $0.2 \%$ EDTA-saline ( $1 \%$ albumin), centrifuged at $280 \mathrm{~g}$ for $15 \mathrm{~min}$ $\left(4^{\circ} \mathrm{C}\right)$, and the platelet-rich supernate removed. This step was repeated once. The sedimented cells, suspended in citrate-saline-albumin, were separated with Ficoll-Hypaque and washed as described above. 
Human platelets were obtained from citrated blood as described (17), with minor modifications. In brief, platelet-rich plasma, obtained after centrifugation at $280 \mathrm{~g}$ for $15 \mathrm{~min}$, was centrifuged for $10 \mathrm{~min}$ at $180 \mathrm{~g}$. This step was repeated to eliminate remaining leukocytes and erythrocytes. $1 \mathrm{ml}$ of citrate solution ( $38 \mathrm{mM}$ citric acid, $75 \mathrm{mM}$ sodium citrate) was added for every $10 \mathrm{~g}$ of platelet-rich plasma; the suspension was centrifuged at $2,000 \mathrm{~g}(10 \mathrm{~min})$ and washed twice in Tris-citrate $(63 \mathrm{mM}$ Tris, $95 \mathrm{mM} \mathrm{NaCl}, 5 \mathrm{mM} \mathrm{KCl}, 12 \mathrm{mM}$ citric acid, $\mathrm{pH}$ 6.4). The final pellet was resuspended to the desired concentration in $0.15 \mathrm{M} \mathrm{NaCl}$. Platelet-leukocyte mixtures studied always originated from the same donor.

Cells were enumerated electronically (Coulter Electronics Inc., Hialeah, FL) or by phase microscopy. Purity of platelet or mononuclear cell preparations was established by microscopic examination of stained smears (Wright-Giemsa). Platelet/mononuclear ratios were established by cell counting, and included those platelets that were seen adhering to monocytes. Monocytes were further differentiated by nonspecific esterase staining (18). The average mononuclear cell preparation contained $25 \%$ monocytes.

Cells were incubated at $1 \times 10^{7}$ mononuclear cells $/ \mathrm{ml}$ in medium 199 (M. A. Bioproducts, Walkersville, MD) containing $50 \mathrm{U}$ penicillin and $50 \mu \mathrm{g}$ streptomycin $/ \mathrm{ml}$ at $37^{\circ} \mathrm{C}$ in stoppered, sterile, pyrogen-free tubes $(17 \mathrm{~h})$. After incubation, cells were sonically disrupted before testing.

Sodium arachidonate, linoleate, linolenate, and dihomogamma-linolenate were purchased from Nu-Chek Prep, Inc. (Elysian, MN) and dissolved in distilled water before use. The resulting stock solutions (13 $\mathrm{mM}$ ) were further diluted in medium 199 to the desired concentrations. These steps were carried out in a nitrogen atmosphere in order to prevent oxidation. Endotoxin (lipopolysaccharide) from Escherichia coli 026B6 (Difco Laboratories Inc., Detroit, MI) was freshly dissolved in medium 199 at the indicated concentrations. 5-HETE, and leukotriene $\mathrm{B}_{4}\left(\mathrm{LTB}_{4}\right)$, leukotriene $\mathrm{C}_{4}\left(\mathrm{LTC}_{4}\right)$, and leukotriene $\mathrm{D}_{4}\left(\mathrm{LTD}_{4}\right)$ were generous gifts from Dr. J. Rokach, (Merck-Frosst Laboratories, Quebec, Canada). 12 HETE was prepared from platelets incubated with arachidonic acid and ionophore A23187 (19). A 12-HETE preparation was also obtained commercially, as was 5,12-dihydroxyeicosatetraenoic acid (5,12-diHETE) (Biomol Research Labs, Inc., Philadelphia, PA). Ionophore was obtained from Calbiochem-Behring, La Jolla, CA.

Procoagulant activity was determined as previously described (15), using the one-stage clotting test and the two-stage clotting assay for tissue factor activity by the method of Nemerson (20), with minor modifications as described (15). A standard preparation of rabbit brain thromboplastin (Difco Laboratories, Inc.) was arbitrarily assigned a value of 1,000 U/ $\mathrm{ml}$. Use of congenitally deficient plasmas demonstrated that $>90 \%$ of the procoagulant activity generated was $\mathrm{TFa}$, since it required Factor VII to express itself (data not shown).

For thin-layer chromatography (TLC) studies, $\left[1-{ }^{14} \mathrm{C}\right]$ arachidonic acid (New England Nuclear, Boston, MA) was prepared as described (17) and added to cell preparations in place of cold arachidonate. The test preparations contained mononuclear cells with or without endotoxin in the presence or absence of platelets. Platelets were obtained from donors who had taken $650 \mathrm{mg}$ of aspirin $3 \mathrm{~h}$ before venipuncture. Reactions were stopped at $5 \mathrm{~min}$ by addition of chloroform/methanol, 2: 5. Samples were acidified with $1 \mathrm{M}$ citric acid and lipids extracted as previously described (17).

Lipid extracts were chromatographed on activated $\left(1 \mathrm{~h}, 110^{\circ} \mathrm{C}\right)$ silica gel $\mathrm{G}$ plates (Analtech, Inc., Newark, DE) along with standards, using chloroform/methanol/acetic acid/water (90:8:1:0.8) as solvent (17).

Glassware and reagents were sterilized and rendered pyrogen-free by heating at $180^{\circ} \mathrm{C}$ for $3 \mathrm{~h}$ whenever possible. Reagents were always dissolved in sterile pyrogen-free solvents. Sterile pyrogen-free working conditions were scrupulously observed in order to avoid any contamination by endotoxin. Reagents were routinely tested for endotoxin contamination with the limulus assay (Pyrogent; Mallinckrodt Inc., St. Louis, $\mathrm{MO}$ ) and were negative at the level of $0.1 \mathrm{ng} / \mathrm{ml}$.

All results represent the average of at least three separate experiments, unless otherwise indicated.

\section{Results}

Effects of arachidonic acid on mononuclear cell procoagulant activity. No procoagulant activity developed when arachidonate alone was added to mononuclear cell preparations. This indicated that the arachidonic acid could not activate mononuclear cells directly and that it was also free of endotoxin. In sharp contrast, arachidonate consistently enhanced TFa when endotoxin was present (Table I). Among a series of fatty acids, the enhancing effect was only observed with arachidonic acid and occurred in a dose-dependent manner (Fig. 1). However, at concentrations of arachidonic acid that exceeded $50 \mu \mathrm{M}$, cell lysis occurred. This was accompanied by a sharp decrease in TFa generation.

The other fatty acids studied (linoleic, linolenic, and dihomogamma-linolenic) had no enhancing effect on TFa, and in fact, even demonstrated suppressive properties (Fig. 1). These results suggested a unique role for arachidonate in amplifying TFa generation. Therefore, an investigation of platelet eicosanoids as participants in the amplification of TFa generation was undertaken.

Effects of platelets and arachidonate on mononuclear cell procoagulant activity. Platelets stimulated the induction of TFa by mononuclear cells, and this effect was greatly enhanced by either arachidonic acid or endotoxin (Table II). The potentiating effect of platelets and arachidonate was studied in greater detail by addition of platelets to mononuclear cell preparations. For example, when mononuclear cells were incubated with platelets in a ratio of 0.35 platelets/mononuclear cell, less than $10 \mathrm{U} \mathrm{TFa}$ was generated (Fig. 2, MN). However, when the platelet/mononuclear cell ratio was increased to 5,10 , or 20 platelets/mononuclear cell, there was a corresponding increase in TFa, approaching $250 \mathrm{U}$ for 20 platelets/mononuclear cell. It is important to note that this activity was greater than that induced by endotoxin alone in the near absence of platelets $(0.35$ platelets/ mononuclear cell) (Fig. 2, MN + E). In control experiments (data not shown), we confirmed previously reported results that platelets did not generate TFa in the absence of leukocytes (15).

The effect of adding arachidonic acid $(10 \mu \mathrm{M})$ to mixtures of mononuclear cells and platelets on TFa generation and the influence of the ratio of platelets to mononuclear cells on these

Table I. Effect of Arachidonate on the Procoagulant Activity of Mononuclear Cells

\begin{tabular}{lll}
\hline Test substances & $\begin{array}{l}\text { One-stage test } \\
\text { (clotting time) }\end{array}$ & TFa \\
\hline $\begin{array}{l}\text { Mononuclear cells + medium } \\
\quad\end{array}$ & $s$ & $U$ \\
$\quad 199$ & 134 & 6 \\
$\begin{array}{l}\text { Mononuclear cells } \\
\quad+\text { arachidonate }\end{array}$ & 61 & 6 \\
$\begin{array}{l}\text { Mononuclear cells + endotoxin } \\
\text { Mononuclear cells + endotoxin } \\
\quad+\text { arachidonate }\end{array}$ & 36 & 423 \\
\hline
\end{tabular}

$1 \times 10^{7}$ mononuclear cells $/ \mathrm{ml}$ in medium 199 were incubated with endotoxin $(0.1 \mu \mathrm{g} / \mathrm{ml})$ in the presence or absence of $10 \mu \mathrm{M}$ arachidonate. After incubation for $17 \mathrm{~h}\left(37^{\circ} \mathrm{C}\right)$, cells were sonicated and coagulation studies performed. In these preparations, there were $\sim 2$ platelets/leukocyte. 


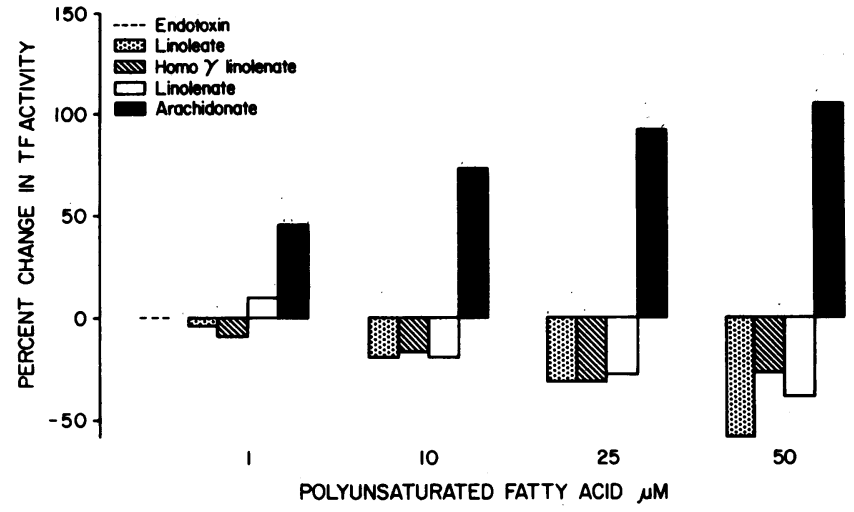

Figure 1. Effect of different polyunsaturated fatty acids on development of TFa in mononuclear cells. $1 \times 10^{7}$ mononuclear cells $/ \mathrm{ml}$ in medium 199 were incubated with endotoxin $(0.1 \mu \mathrm{g} / \mathrm{ml})$ in the presence of the indicated fatty acid. 2 platelets/mononuclear cell were present in these preparations. TFa was consistently enhanced by arachidonic acid in a dose-dependent manner. Other fatty acids had no effect, or were inhibitory. Arachidonate or an eicosanoid metabolized therefrom was responsible for the observed enhancement of TFa.

results is demonstrated in Fig. $2(\mathrm{MN}+\mathrm{AA})$. In the near absence of platelets, addition of arachidonate had little or no effect on TFa. However, upon addition of incremental quantities of platelets, sharp increases in TFa generation occurred. Thus, at a ratio of 20 platelets/mononuclear cell, TFa increased to 1,200 $\mathrm{U}$ (Fig. 2, MN + AA).

As expected, addition of endotoxin alone to mononuclear cells induced TFa. As in the above experiments, enhancement of TFa was dependent upon the platelet/mononuclear cell ratio (Fig. 2, MN + E). The TFa thereby produced was even further augmented by the presence of $10 \mu \mathrm{M}$ arachidonate (Fig. 2, MN $+\mathbf{E}+\mathbf{A A})$.

Table II. Effect of Platelets and Arachidonate on the Procoagulant Activity of Mononuclear Cells

\begin{tabular}{|c|c|c|}
\hline Test substances & $\begin{array}{l}\text { One-stage test } \\
\text { (clotting time) }\end{array}$ & TFa \\
\hline & $s$ & $U$ \\
\hline Mononuclear cells + platelets & 46 & 316 \\
\hline \multicolumn{3}{|l|}{ Mononuclear cells + platelets } \\
\hline + arachidonate & 29 & 1,290 \\
\hline \multicolumn{3}{|l|}{ Mononuclear cells + platelets } \\
\hline + endotoxin & 24 & 1,090 \\
\hline \multicolumn{3}{|l|}{$\begin{array}{l}\text { Mononuclear cells + platelets } \\
\quad+\text { endotoxin }\end{array}$} \\
\hline + arachidonate & 22 & 1,570 \\
\hline \multicolumn{3}{|l|}{ Mononuclear cells } \\
\hline + endotoxin & 47 & 300 \\
\hline \multicolumn{3}{|l|}{ Mononuclear cells } \\
\hline + medium 199 & 116 & 8 \\
\hline
\end{tabular}

$1 \times 10^{7}$ mononuclear cells $/ \mathrm{ml}$ were incubated with or without endotoxin $(0.1 \mu \mathrm{g} / \mathrm{ml})$ and $10 \mu \mathrm{M}$ arachidonate in the presence of $2 \times 10^{8}$ platelets $/ \mathrm{ml}$ and processed as indicated in Table $\mathrm{I}$.
Additive effect of arachidonic acid and endotoxin on TFa in the presence of a constant quantity of platelets. The enhancing effect of arachidonate on TFa generation by endotoxin-stimulated mononuclear cells was studied in greater detail in the setting of a constant number of platelets (Fig. 3). At a ratio of 6 platelets/ mononuclear cell, addition of endotoxin led to a dose-dependent increase in $\mathrm{TFa}$, with a plateau appearing between 100 and 1,000 $\mathrm{ng} / \mathrm{ml}$ endotoxin. However, at each concentration of endotoxin, TFa was further enhanced dose dependently by arachidonate. Specifically, a greater than threefold increase in TFa was achieved when $20 \mu \mathrm{M}$ arachidonate was added to any quantity of endotoxin in the incubation mixture. It is notable that with only 1 ng endotoxin and $20 \mu \mathrm{M}$ arachidonate more TFa was generated than with as much as $1,000 \mathrm{ng}$ endotoxin in the absence of arachidonate. These experiments indicated that the stimulatory effects of arachidonate and endotoxin were different with regard to TFa generation (Fig. 3) and suggested a role for eicosanoids in modulation of TFa.

Effect of aspirin on the development of TFa. The major platelet oxygenation pathways of arachidonate are catalyzed by a lipoxygenase and cyclooxygenase. Cyclooxygenase activity is inhibited by aspirin. In order to identify possible effects of cyclooxygenase inhibition, blood was obtained from volunteers before and $3 \mathrm{~h}$ after aspirin ingestion. The effect on mononuclear TFa as induced or enhanced by several biological components

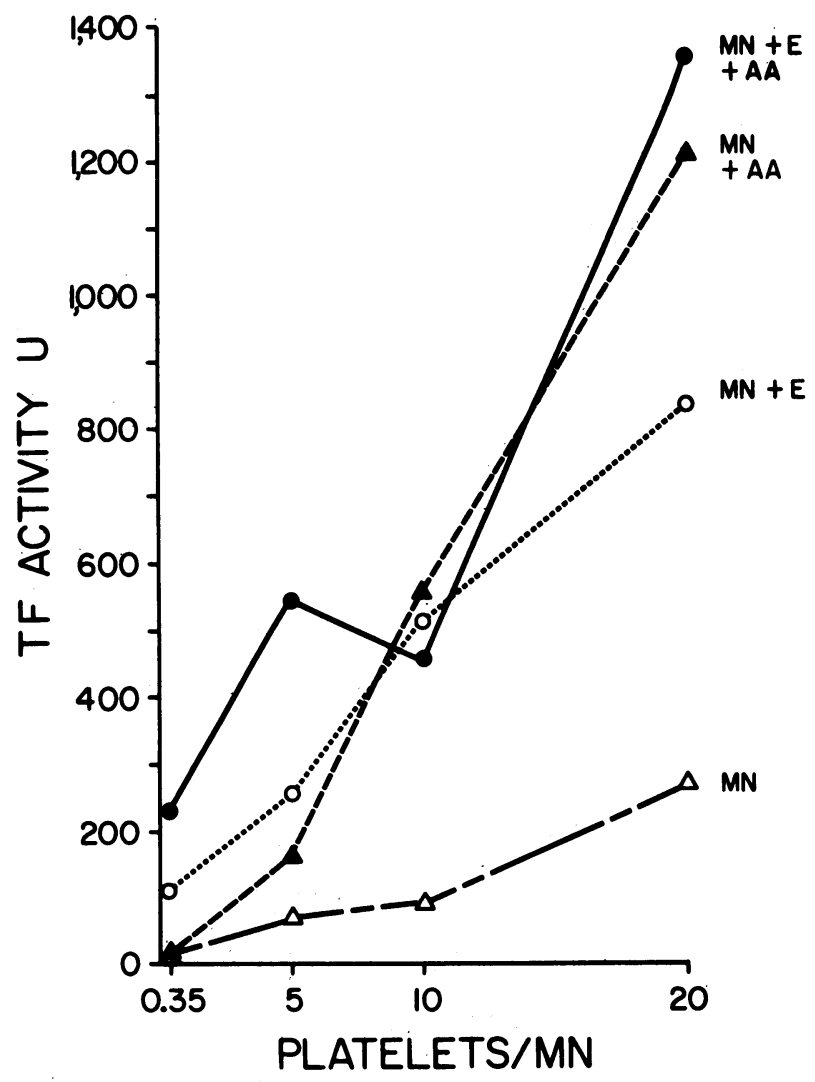

Figure 2. Effect of platelets and arachidonate (AA) on TFa of mononuclear cells $(\mathrm{MN}) .1 \times 10^{7} \mathrm{MN} / \mathrm{ml}$ were incubated with $\mathrm{AA}(10 \mu \mathrm{M})$, endotoxin $(E)(0.1 \mu \mathrm{g})$, and increasing quantities of platelets. Incremental addition of platelets to leukocytes resulted in a corresponding increase in TFa. Addition of AA to these platelet-leukocyte suspensions resulted in sharp increases in TFa. 


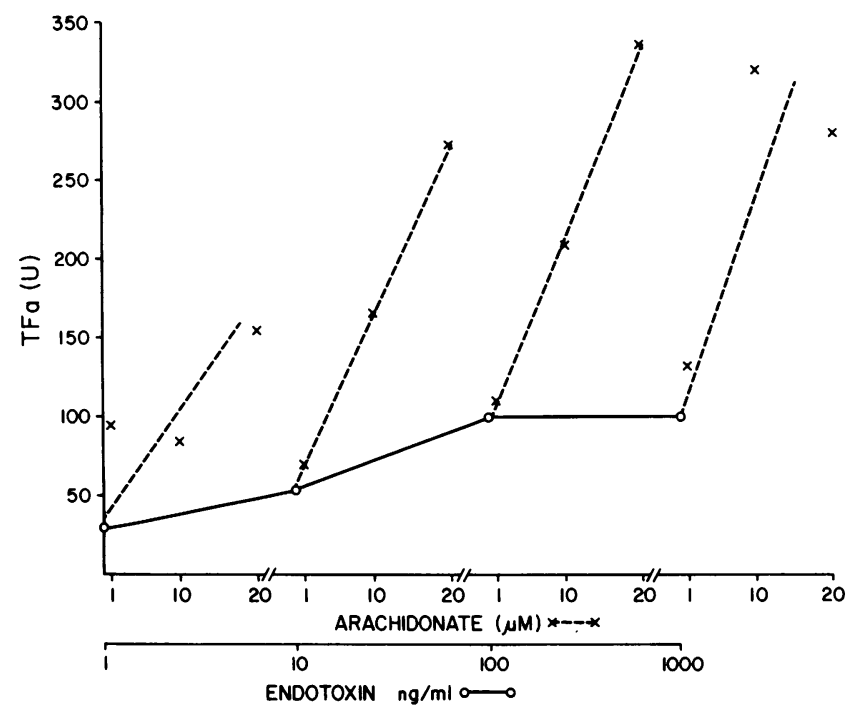

Figure 3. Modulation of TFa by arachidonate and endotoxin in the presence of a constant number of platelets. Preparations containing 1 $\times 10^{7}$ mononuclear cells $/ \mathrm{ml}$ and 6 platelets/mononuclear cell were incubated with the indicated quantities of endotoxin. TFa increased in a dose-dependent manner in the range of $1-100 \mathrm{ng}$ endotoxin ( 0 , solid line). Amplification of TFa was dose-dependent for each level of arachidonate ( $x$, dashed lines). Thus, the stimulatory effect of arachidonate was additive to that of endotoxin at each incremental level of the latter.

(endotoxin, arachidonate, platelets) was then studied (Fig. 4). Aspirin had no inhibitory effect under any experimental circumstances, but, instead, enhanced TFa in the presence of platelets. This indicates that the contribution of platelets to TFa generation was independent of the cyclooxygenase pathway and that a lipoxygenase product such as 12-HETE could be involved.

Studies on the role of $12-H E T E .\left[{ }^{14} \mathrm{C}\right]$ arachidonate $(10 \mu \mathrm{M})$ was added to mononuclear cells in combination with inducers and modulators such as endotoxin or platelets in various combinations. These experiments were carried out in duplicate to measure eicosanoid generation and TFa in identical samples.
When examined by radio-TLC, all samples in which high TFa was generated yielded 12-HETE, the major metabolite of the platelet lipoxygenase pathway (Fig. 5). These results corroborated our hypothesis (based on the lack of inhibition of TFa generation by aspirin pretreatment) that 12 -HETE was involved as an enhancing agent in TFa generation.

To further test this hypothesis, 12-HETE was substituted for platelets in our test system. 12-HETE was added to mononuclear cell preparations containing $<0.1$ platelet/mononuclear cell. In the absence of endotoxin, 12-HETE had only a slight effect on leukocyte TFa (Fig. 6). However, in the presence of endotoxin, TFa was enhanced by 12-HETE in a dose-dependent manner (Fig. 6). $10 \mu \mathrm{M}$ 12-HETE generated threefold greater TFa than the optimal quantity of endotoxin alone. At higher concentrations of 12-HETE, a plateau effect was achieved. It should be noted that the highest concentration of 12-HETE studied in these experiments $(20 \mu \mathrm{M})$ can be generated by $2 \times 10^{8}$ platelets $/ \mathrm{ml}$, equivalent to a ratio of 20 platelets/mononuclear cell.

In addition to 12-HETE, we examined the effects on TFa generation of 5-lipoxygenase products that can be formed by leukocytes, such as 5-hydroxyeicosatetraenoic acid (5-HETE), $\mathrm{LTB}_{4}, \mathrm{LTC}_{4}, \mathrm{LTD}_{4}$, and 5,12-diHETE. When tested under identical conditions, and at concentrations ranging from 1 to $1,000 \mathrm{nM}$, no effect on TFa was discernable (Table III). This is in sharp contrast to the chemotactic, chemokinetic, and spasmogenic activities leukotrienes exert at similar concentrations $(21,22)$.

\section{Discussion}

In the present report we demonstrate that arachidonic acid amplified endotoxin-induced mononuclear cell TFa generation (Fig. 1, Table I). This enhancement by arachidonate was strikingly higher in the presence of increasing numbers of platelets (Fig. 2). The effect was even more pronounced when platelets from volunteers who had ingested aspirin were used (Fig. 4).

Large quantities of labeled 12-HETE were generated when aspirin-treated platelets were incubated with mononuclear cells and radiolabeled arachidonate (Fig. 5). When added to mono-

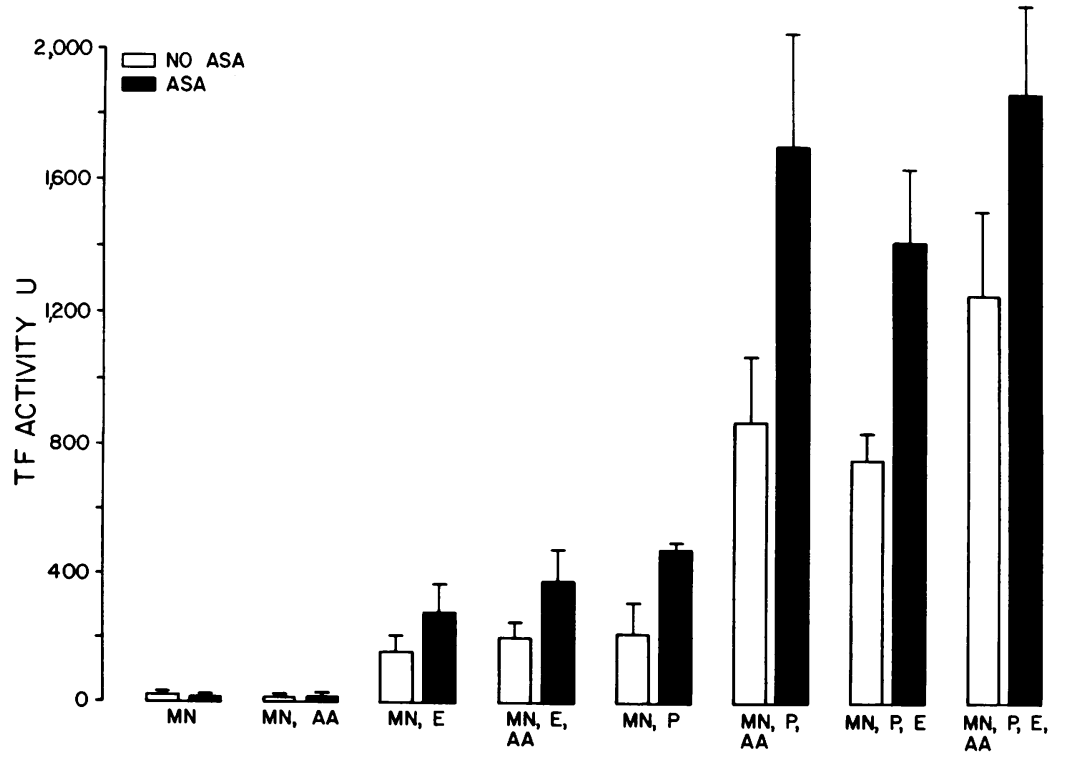

Figure 4. Effect of aspirin (ASA) on TFa of mononuclear cells $(\mathrm{MN})$. Venipuncture was carried out on the same donor before and $3 \mathrm{~h}$ after ingestion of $650 \mathrm{mg}$ ASA. $1 \times 10^{7} \mathrm{MN} / \mathrm{ml}$ (containing 0.35 platelets $(\mathrm{P}) /$ $\mathrm{MN}$ ) were incubated as indicated with $0.1 \mu \mathrm{g}$ endotoxin $(\mathrm{E}) / \mathrm{ml}$ and $10 \mu \mathrm{M}$ arachidonate (AA). When $\mathrm{P}$ were added, $2 \times 10^{8} \mathrm{P} / \mathrm{ml}$ were used. After ASA ingestion, TFa generation was enhanced in the presence of $P$. Bars indicate the mean \pm SEM. 


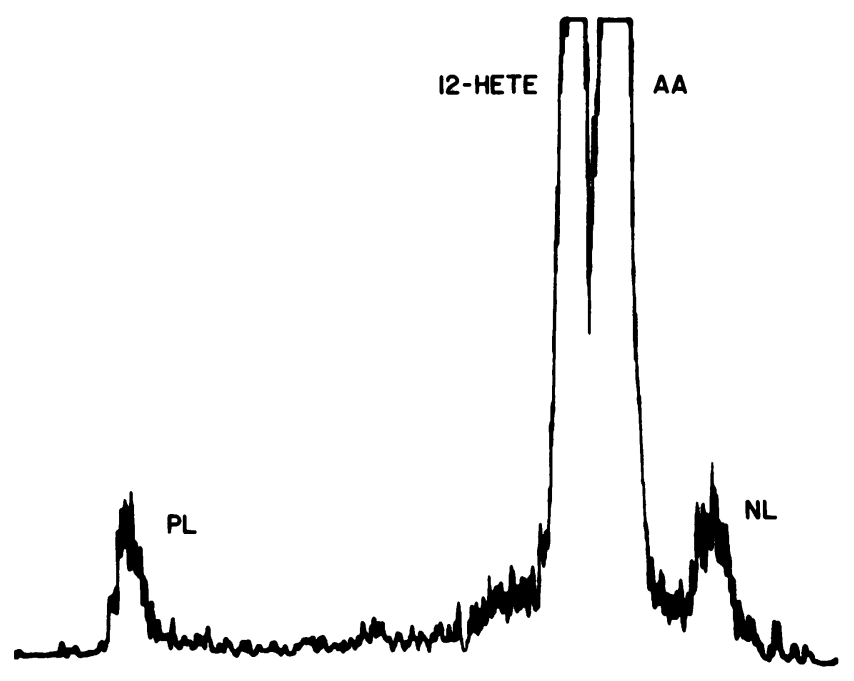

Figure 5. Radio-TLC of lipid extract from an incubation mixture containing $1 \times 10^{7}$ mononuclear cells/ml, $10 \mu \mathrm{M}\left[1-{ }^{14} \mathrm{C}\right]$ arachidonic acid in the presence or absence of endotoxin $(0.1 \mu \mathrm{g} / \mathrm{ml})$ and $2 \times 10^{8}$ platelets/ml. The donor had ingested aspirin before venipuncture. PL, phospholipids; NL, neutral lipids; AA, unmetabolized arachidonic acid.

nuclear cells, unlabeled 12-HETE (platelet-derived or synthetic) markedly enhanced endotoxin-induced TFa. Importantly, neither arachidonate nor 12-HETE could induce TFa from mononuclear cells by themselves. This indicated that the arachidonic acid and 12-HETE preparations were endotoxin-free, a finding further corroborated by the negative limulus test. Thus, arachidonic acid and 12-HETE act as enhancers, rather than initiators, of TFa generation.

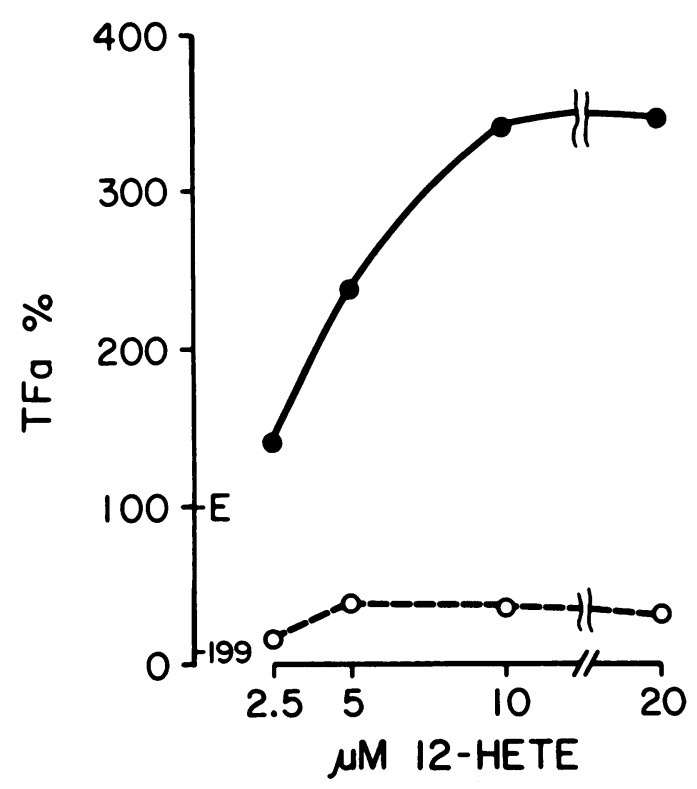

Figure 6. Effect of 12-HETE on TFa of mononuclear cells in the presence or absence of endotoxin (E) $(0.1 \mu \mathrm{g} / \mathrm{ml})$. Addition of $10 \mu \mathrm{M} 12$ HETE induced formation of threefold greater amounts of TFa. The enhancement achieved by $20 \mu \mathrm{M}$ 12-HETE can be generated by 2 $\times 10^{8}$ platelets $/ \mathrm{ml}$. This is equivalent to a ratio of 20 platelets/mononuclear cell. 12-HETE (- - O- -); 12-HETE + endotoxin $(\longrightarrow-\longrightarrow)$; 199, medium 199.
Table III. Effect of 5-HETE, LTB 4, LTC $4, L T D_{4}$, and 5,12diHETE on TFa of Endotoxin-stimulated Mononuclear Cells

\begin{tabular}{lrrrr}
\hline & \multicolumn{4}{l}{$\begin{array}{l}\text { Two-stage clotting assay } \\
\text { (percent of stimulated control) }\end{array}$} \\
\hline Test substances $(n M)$ & 1 & 10 & 100 & 1,000 \\
& 98 & 105 & 87 & 72 \\
5-HETE & 120 & 123 & 123 & 68 \\
LTB $_{4}$ & 119 & 119 & 117 & 87 \\
LTC $_{4}$ & 99 & 95 & 122 & - \\
LTD $_{4}$ & 107 & 107 & 110 & 127 \\
5,12-diHETE & & & & \\
\end{tabular}

$1 \times 10^{7}$ mononuclear cells, exposed to $0.1 \mu \mathrm{g} / \mathrm{ml}$ endotoxin, were incubated with the indicated quantities of 5-lipoxygenase products.

At concentrations greater than $50 \mu \mathrm{M}$ arachidonate, cell lysis occurred and TFa generation was abolished. This emphasizes that TFa generation required an intact, metabolically active cell, and that arachidonate was not exerting a detergent-like effect. The demonstration that other fatty acids such as linoleic, linolenic, and dihomogamma-linolenic had no enhancing capabilities in TFa development (Fig. 1) served as further evidence that eicosanoids derived from arachidonate played a unique role in TFa generation.

Arachidonate is an integral cell membrane component, where it is esterified to phospholipids and liberated by phospholipases upon cell stimulation. In platelets, free arachidonic acid serves to activate the cyclooxygenase and lipoxygenase. However, lipoxygenation does not occur in leukocytes in the absence of a strong agonist, such as ionophore $(23,24)$. In our experiments, free arachidonate alone had no effect on leukocyte TFa generation in the absence of platelets, suggesting a requirement for metabolic conversion of added arachidonate.

Administration of aspirin, as carried out in our studies, is followed by irreversible inactivation of platelet cyclooxygenase. Lipoxygenase is not inhibited, and continues to oxygenate free arachidonate until it is no longer available (25). Thus, in the presence of aspirin, arachidonate is diverted toward hydroxy acid production $(24,25)$. Aspirin-treatment exerted an enhancing effect on TFa generation (Fig. 4), suggesting that the lipoxygenase, but not the cyclooxygenase pathway was involved in generation of mononuclear cell TFa.

Enhancement of endotoxin-induced TFa, as demonstrated above, is a novel function of platelet-derived 12-HETE, in addition to its known chemotactic activities (26). This effect of 12HETE is specific, since 5-HETE and 5-lipoxygenase-derived leukotrienes were inactive in our test system. This enhancement effect of 12-HETE has functional and clinical implications, because this eicosanoid is produced in abundance by stimulated platelets, whether or not a nonsteroidal antiinflammatory agent has been administered (27). The importance of this effect is further emphasized by recent observations correlating leukocyte procoagulant activity with mortality in patients with meningococcemia (3).

In our experiments, cyclooxygenase inhibition increased leukocyte TFa generation. It was recently demonstrated that lipoxygenase inhibitors impede generation of monocyte procoagulant activity (28), while cyclooxygenase inhibition had no impeding effect $(28,29)$. A relationship between eicosanoids and $\mathrm{TFa}$ in rabbit alveolar macrophages has been proposed (30). It 
was also reported that a platelet-derived product can modulate fibroblast TFa (31).

In conclusion, our studies identified platelet 12-HETE as a potent cofactor for TFa generation. This constitutes a new aspect of cell-cell interactions via eicosanoid pathways as a contributory factor in mononuclear cell TFa synthesis.

\section{Acknowledgments}

We thank Dr. J. Rokach from Merck-Frosst Laboratories, Quebec, Canada, for the generous gifts of 5-HETE, $\mathrm{LTB}_{4}$ and $\mathrm{LTD}_{4}$; and Lenore $\mathrm{B}$. Safier, Harris L. Ullman, and Naziba Islam for invaluable assistance.

This work was supported in part by the Veterans Administration, by grants from the National Institutes of Health (HL-13155, HL-1882810 [Specialized Center of Research], HL-29034, and RR-05396), and by the New York Heart Association.

Dr. R. Lorenzet was supported by a grant from the European Economic Community.

\section{References}

1. Niemetz, J., and K. Fani. 1971. Role of leukocytes in blood coagulation and the generalized Shwartzman reaction. Nat. New Biol. 232: 247-248.

2. Niemetz, J., and K. Fani. 1973. Thrombogenic activity of leukocytes. Blood. 42:47-59.

3. Osterud, B., and T. Flaegstad. 1983. Increased tissue thromboplastin activity in monocytes of patients with meningococcal infection: related to an unfavorable prognosis. Thromb. Haemostasis. 49:5-7.

4: Muhlfelder, T., J. Niemetz, D. Kreutzer, D. Beebe, P. A. Ward, and S. L. Rosenfeld. 1979. C5 chemotactic fragment induces leukocyte production of tissue factor activity-a link between complement and coagulation. J. Clin. Invest. 63:147-150.

5. Edwards, R. L., F. R. Rickles, and A. M. Bobrove. 1979. Mononuclear cell tissue factor: cell of origin and requirement for activation. Blood. 54:359-370.

6. Levy, G. A., B. S. Schwartz, K. Curtiss, and T. S. Edgington. 1981. Plasma lipoprotein induction and suppression of the generation of cellular procoagulant activity in vitro. J. Clin. Invest. 67:1614-1622.

7. Schwartz, B. S., G. A. Levy, K. Curtiss, D. S. Fair, and T. S. Edgington. 1981. Plasma lipoprotein induction and suppression of the generation of cellular procoagulant activity in vitro. J. Clin. Invest. 67: 1650-1658.

8. Rothberger, H., T. S. Zimmerman, and J. H. Vaughan. 1978. Increased production and expression of tissue thromboplastin-like procoagulant activity in vitro by allogeneically stimulated leukocytes. $J$. Clin. Invest. 62:649-655.

9. Lorenzet, R., G. Peri, D. Locati, P. Allavena, M. Colucci, N. Semeraro, A. Mantovani, and M. B. Donati. 1983. Generation of procoagulant activity by mononuclear phagocytes: a possible mechanism contributing to blood clotting activation within malignant tissues. Blood. 62:271-273.

10. Garg, S. K., and J. Niemetz. 1973. Tissue factor activity of normal and leukemic cells. Blood. 42:729-735.

11. Rivers, R. P. A., W. E. Hathaway, and W. L. Weston. 1975. The endotoxin-induced coagulant activity of human monocytes. Br. J. Haematol. 30:311-316.

12. Levy, G. A., and T. S. Edgington. 1980. Lymphocyte cooperation is required for amplification of macrophage procoagulant activity. $J$. Exp. Med. 151:1232-1244.
13. Osterud, B., and E. Bjorklid. 1982. The production and availability of tissue thromboplastin in cellular populations of whole blood exposed to various concentrations of endotoxin: an assay for detection of endotoxin. Scand. J. Haematol. 29:175-184.

14. Pinder, P. B., J. A. Hunt, and L. R. Zacharski. 1985. In vitro stimulation of monocyte tissue factor activity by autologous platelets. Am. J. Hematol. 19:317-325.

15. Niemetz, J., and A. J. Marcus. 1974. The stimulatory effect of platelets and platelet membranes on the procoagulant effect of leukocytes. J. Clin. Invest. 54:1437-1443.

16. Boyum, A. 1968. Isolation of leukocytes from human blood. Scand. J. Clin. Lab. Invest. 21:77-89.

17. Marcus, A. J. 1983. Measurements of platelet function. In Methods in Hematology. L. A. Harker, and T. S. Zimmerman, editors. Vol. 8. Churchill Livingstone, New York. 126-143.

18. Koski, R., D. G. Poplack, and R. M. Blaese. 1976. A non-specific esterase stain for the identification of monocytes and macrophages. In In vitro Methods in Cell-mediated and Tumor Immunity. B. R. Bloom, and J. R. David, editors. Academic Press, New York. 359-362.

19. Marcus, A. J., L. B. Safier, H. L. Ullman, M. J. Broekman, N. Islam, T. D. Oglesby, and R. R. Gorman. 1984. 12S, 20-Dihydroxyicosatetraenoic acid: a new icosanoid synthesized by neutrophils from 12S-hydroxyicosatetraenoic acid produced by thrombin- or collagenstimulated platelets. Proc. Natl. Acad. Sci. USA. 81:903-907.

20. Nemerson, Y., and T. H. Spaet. 1964. The activation of Factor $\mathrm{X}$ by extracts of rabbit brain. Blood. 23:657-664.

21. Ford-Hutchinson, A. W., A. M. Bray, M. E. Doig, M. V. Shipley, and M. J. H. Smith. 1980. Leukotriene $B_{4}$, a potent chemokinetic and aggregating substance released from polymorphonuclear leukocytes. $\mathrm{Na}$ ture (Lond.). 286:264-265.

22. Piper, P. J. 1983. Pharmacology of leukotrienes. Br. Med. Bull. 39:255-259.

23. Samuelsson, B. 1983. Leukotrienes: mediators of immediate hypersensitivity reactions and inflammation. Science (Wash. DC). 220: 568-575.

24. Marcus, A. J., M. J. Broekman, L. B. Safier, H. L. Ullman, N. Islam, C. N. Serhan, L. E. Rutherford, H. M. Korchak, and G. Weissmann. 1982. Formation of leukotrienes and other hydroxy acids during platelet-neutrophil interactions in vitro. Biochem. Biophys. Res. Commun. 109:130-137.

25. Hamberg, M., and G. Hamberg. 1980. On the mechanism of the oxygenation of arachidonic acid by human platelet lipoxygenase. Biochem. Biophys. Res. Commun. 95:1090-1097.

26. Goetzl, E. J., J. M. Woods, and R. R. Gorman. 1977. Stimulation of human eosinophil and neutrophil polymorphonuclear leukocyte chemotaxis and random migration by 12-L-hydroxy-5,8,10,14-eicosatetraenoic acid. J. Clin. Invest. 59:179-183.

27. Marcus, A. J. 1984. The eicosanoids in biology and medicine. J. Lipid Res. 25:1511-1516.

28. Crutchley, D. J. 1984. Effect of inhibitors of arachidonic acid metabolism on thromboplastin activity in human monocytes. Biochem. Biophys. Res. Commun. 119:179-184.

29. Prydz, H., and T. Lyberg. 1980. Effect of some drugs on thromboplastin (Factor III) activity of human monocytes in vitro. Biochem. Pharmacol. 29:9-14.

30. Sitrin, R. G., H. B. Kaltreider, and M. E. Goldyne. 1984. Prostaglandin $\mathrm{E}$ is required for the augmentation of procoagulant activity of LPS-stimulated rabbit alveolar macrophages. Immunology. 132:867-871.

31. Smariga, P. E., and J. R. Maynard. 1982. Purification of a platelet protein which stimulates fibrinolytic inhibition and tissue factor in human fibroblasts. J. Biol. Chem. 257:11960-11965. 